\title{
Accurate battery model parameter identification using heuristic optimization
}

Mohd Afifi Jusoh, Muhamad Zalani Daud

Faculty of Ocean Engineering Technology and Informatics, Universiti Malaysia Terengganu, Malaysia

\begin{tabular}{|c|c|}
\hline Article Info & ABSTRACT \\
\hline Article history: & This paper presents an accurate Lithium-ion battery model representation in \\
\hline Received Jul 17, 2019 & $\begin{array}{l}\text { Matlab/Simulink. The Tremblay's battery model was used as a BES model } \\
\text { platform, where the determination of the model parameters was obtained }\end{array}$ \\
\hline Revised Sep 27, 2019 & based on heuristic optimization approach. This approach is simple but more \\
\hline Accepted Nov 29, 2019 & $\begin{array}{l}\text { accurate compared to the conventional method. In the classical method, it } \\
\text { reguires the user to manually select the battery model parameters from }\end{array}$ \\
\hline Keywords: & $\begin{array}{l}\text { relevant points on the manufacturer discharge curves. However, this way of } \\
\text { battery parameters extraction normally exposed to the human error and }\end{array}$ \\
\hline Battery parameter & would easily result in an inaccurate selection of battery parameters for the \\
\hline Energy storage & BES simulation studies. Therefore, an easy and accurate approach using \\
\hline Heuristic optimization & introduced. The simulation studies utilized three different optimization \\
\hline Lithium-ion battery & $\begin{array}{l}\text { algorithms for comparison purposes, i.e. 1) Particle Swarm Optimization } \\
\text { (PSO), 2) Gravitational Search Algorithm (GSA), and 3) Genetic Algorithm } \\
\text { (GA). The performance of BES model discharge accuracy with respect to the } \\
\text { test data from three different algorithms was compared and the results } \\
\text { showed that the GA approach gives the best results in terms of accuracy and } \\
\text { execution time. Finally, the validated results of GA-optimized battery model } \\
\text { showed the accuracy of } 98 \% \text { compared to the conventional approach. }\end{array}$ \\
\hline
\end{tabular}

This is an open access article under the CC BY-SA license.

\section{Corresponding Author:}

Muhamad Zalani Daud,

Faculty of Ocean Engineering Technology and Informatics,

Universiti Malaysia Terengganu,

Mengabang Telipot, 21030 Kuala Nerus, Terengganu Malaysia.

Email: zalani@umt.edu.my

\section{INTRODUCTION}

Battery energy storage (BES) system is an important element in the renewable energy (RE) system and electric vehicles (EV) applications $[1,2]$. In solar photovoltaic (PV) system application, the integration of BES with the PV system is one proven method in mitigating the output power fluctuations of PV sources [3]. Currently, there are various types of batteries commercially available for BES such as Lead-Acid (LA), Lithium-ion (Li-ion), Nickel Metal Hydride (NiMH), Nickel Cadmium (NiCd), Sodium Sulphur (NaS) and many more $[4,5]$. Li-ion batteries have outstanding applications especially in the operation of plug-in hybrid electric vehicles (PHEVs) and power grid applications. This is due to its characteristics of high energy density, high charge and discharge ability, low self-discharge loss, longest cycle life, highest efficiency, and no memory effects compared to the all other battery technologies $[4,6]$.

Recently, a simulation study is a frequently used technique to design and develop a high efficiency and robust control strategy of the BES system, particularly in electric vehicles and power system applications. The simulation technique can reduce the cost of commercialization of new technology as it can 
avoid the unnecessary procedures in testing so as avoiding the purchase of expensive measuring instruments. Simulation studies of BES control system have been extensively carried out in the past [7-13]. In this regard, several battery models were proposed to further evaluate and develop the BES control system. An accurate battery model is needed as it has direct influence to the state-of-charge which can affect the robustness of the BES control system [12-14].

In [15], a brief overview of several battery models for various applications are presented. The battery models are classified into several categories: simple model, Thevenin-based model, impedance-based model, runtime-based model, combined electrical circuit-based model, and generic-based models. A generic battery model is accurate and appropriate for all types of battery energy storages. In [16], an improved and easy to use generic battery model is presented for electric vehicle applications. However, the parameters of the battery model need to be manually obtained from battery manufacturer discharge curve. This results in poor model performance when implemented in the simulation software. The accuracy of the battery parameters extraction has direct effects on the performance of the battery model. To accurately estimate the model parameters, one effective way is by performing parameter extraction from manufacturer discharge curves using optimization approach. A Quantum-behaved Particle Swarm Optimization (QPSO) and Particle Swarm Optimization (PSO) are used to obtaining the Li-ion battery parameters from the manufacturer discharge curve for the electric vehicle application have been presented in [17] and [18], respectively. Whereas, in [19], a parallel Jaya algorithm is applied to estimate the Li-ion battery parameters and the simulation results showed good performance of the developed algorithm. The specific optimization algorithms used in [17-19] however gives challenges to the user with limited access to the optimization codes. An easy to use guideline for such parametric optimization strategy should be developed considering widely available optimization approach. This paper presents parameters estimation strategy of the BES model using widely used heuristic optimization approaches such as Particle Swarm Optimization (PSO) and Genetic Algorithm (GA). In addition, Gravitational Search Algorithm (GSA) is also used for comparison purpose and diversify the results of optimization. The generic battery model [16] of Li-ion type is considered in which its parameters are extracted from the manufacturer discharge curves. Finally, based on the proposed heuristic optimization approaches, the comparison of Li-ion battery model discharge performance is presented.

\section{RESEARCH METHOD}

The present work is carried out from the development of accurate Li-ion battery model. Then, the parameters of the developed Li-ion model are optimized using heuristic optimization methods considering the PSO, GSA, and GA respectively. Then, the optimal Li-ion battery model is validated by comparing the characteristic curves of the optimal Li-ion battery model developed, with the test data from the manufacturer.

\subsection{Development of li-ion battery model}

The Li-ion battery model is implemented according to the Tremblay's generic battery model presented in [16]. This model is high efficiency and can give good performance in studies related to electric vehicles and renewable energy technologies. The model can be represented by using equations to describe the electrochemical behavior of the battery in terms of state-of-charge (SOC), terminal voltage and internal resistance. The formulated equations of the dynamic model are described as follows:

$$
\begin{aligned}
& V_{B a t}=E_{B a t}-R_{\text {int }} I_{B a t} \\
& S O C=100\left(\frac{\int I_{B a t} d t}{Q}\right) \\
& E_{B a t, \text { disc }}=E_{0}-\left[K\left(\frac{Q}{Q-i t} i^{*}\right)\right]-\left[K\left(\frac{Q}{Q-i t} i t\right)\right]+A e^{(-B)(i t)} \\
& E_{\text {Bat,charg }}=E_{0}-\left[K\left(\frac{Q}{i t-0.1 Q} i^{*}\right)\right]-\left[K\left(\frac{Q}{Q-i t} i t\right)\right]+A e^{(-B)(i t)}
\end{aligned}
$$

where $V_{B a t}$ is the battery voltage, $R_{\text {int }}$ is the battery internal resistance, $I_{B a t}$ is the battery current, $Q$ is the cell capacity, $E_{B a t}$ is the battery electromotive force, $E_{B a t, d i s c}$ and $E_{B a t, c h a r g}$ are the battery electromotive force during charge and discharge, $E_{0}$ is the battery open-circuit voltage, $K$ is the polarisation constant/polarisation resistance. The term it can be obtained by integration the battery current, i.e. $\int I_{B a t} \mathrm{dt}$, which is the actual battery current. Whereas, $i^{*}$ is the filtered current. The exponential zone of battery discharge curves are represented by $A$, which is the exponential zone voltage, and $B$ represents the exponential zone time constant inverse. For the battery model, there are several specific assumptions and limitations such as there is no selfdischarge, the nominal capacity and internal resistance are constant, and there are no environmental considerations. From the developed battery model, BES system model can be constructed by series/parallel combination of single battery cell parameters. Table 1 illustrated the transformation of battery cell

Int J Pow Elec \& Dri Syst Vol. 11, No. 1, Mar 2020 : 333 - 341 
parameters, where the number of cells in series $\left(n_{s}\right)$ and parallel $\left(n_{p}\right)$ determines the total output terminal voltage and capacity or total size of a BES system, respectively.

Table 1. Battery parameters transformation

\begin{tabular}{cc}
\hline Parameters (unit) & Value \\
\hline End of nominal zone voltage (V) & $V_{\text {nom }} \times n_{s}$ \\
End of nominal zone capacity (Ah) & $Q_{\text {nom }} \times n_{p}$ \\
Rated capacity (Ah) & $Q_{\text {rated }} \times n_{p}$ \\
Internal resistance $(\Omega)$ & $I_{\text {int }} \times n_{p} / n_{s}$ \\
Maximum capacity (Ah) & $Q_{\max } \times n_{p}$ \\
Fully charged voltage (V) & $V_{\text {full }} \times n_{s}$ \\
Nominal discharge current (A) & $I_{\text {nom, lisc }} \times n_{p}$ \\
End of exponential zone voltage (V) & $V_{\text {exp }} \times n_{s}$ \\
End of exponential zone capacity (Ah) & $Q_{\text {exp }} \times n_{p}$ \\
\hline
\end{tabular}

\subsection{Battery parameters extraction method}

The battery parameters can be approximated by using the manufacturer's data by following the procedures given in [16]. Figure 1 illustrates the battery parameters extraction procedure from the typical discharge curves from the manufacturer. As illustrated in the figure, three important points namely fully charged voltage $\left(V_{\text {full }}\right)$, end of exponential zone $\left(V_{\exp }, Q_{\text {exp }}\right)$ and end of nominal zone $\left(V_{\text {nom }}, Q_{\text {nom }}\right)$ are manually obtained from the figure. From these points, the parameters of $E_{0}, A, B$, and $K$ can be determined. The parameters accuracy from this approach is depends on the accuracy of the points marked on the curves. In practice, it is difficult to identify a correct point on the curves just by using visual analysis. This is because the raw data of the manufacturer discharge curves normally not supplied to the user. Thus, an intelligent approach is a promising way to overcome this issue. By using an optimization approach, a good model design can be achieved according to application needs and can avoid human error. Furthermore, more time can be saved during the parameters extraction procedure.

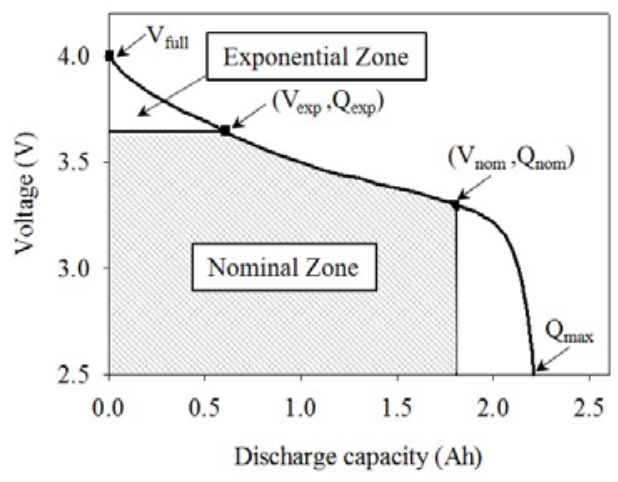

Figure 1. Battery parameters extraction procedure based on the discharge curve of panasonic Li-ion CGR 18650AF battery [20]

\section{OPTIMIZATION OF BATTERY PARAMETERS}

In the optimization process, six optimal parameters needed to be obtained which are $V_{\text {full }}, V_{\exp }, Q_{\exp }$, $V_{\text {nom }}, Q_{\text {nom }}$ and $R_{\text {int }}$. The objective of the optimization problem is to minimize the deviation of the developed battery model discharge curves with the real battery discharge curve data obtained from the manufacturer datasheet. In this regards, the objective function is determined according to (5), where the vector $x$ and $k$ represent the battery parameters and the index of the sampled data, respectively. While, $V_{\text {bat,mod }(k)}$ and $V_{\text {bat,manu }(k)}$ represent the voltage data of the developed battery model and the voltage data of real Li-ion battery from the manufacturer. The optimization problem is solved by three different algorithms which are PSO, GSA, and GA for comparison purposes. The justification for selecting these three algorithms is due to their wide applicability and readily to be implemented in Matlab. These algorithms also have been proven to deliver good optimization accuracy, particularly in battery storage application in renewable energy sources $[7,12,13,21-23]$. 


$$
O F(x)=\min \left|\int\left(V_{\text {bat,mod }}(k)-V_{\text {bat }, \text { manu }}(k)\right)^{2} d t\right|
$$

\subsection{Particle swarm optimization (PSO)}

The PSO algorithm has been invented by Kennedy and Elbert in 1995 [24]. The general process of the PSO algorithm is as illustrated in Figure 2(a). PSO algorithm solves the problem in (5) by having the random population of particle solutions (battery parameters). PSO algorithm optimizes the problem by iteratively moving these particles around in the search-space according to simple mathematical formula as described in (6), (7), (8), where $X_{j}^{k}$ and $X_{j}^{k+1}$ are the previous and updated position of particle $j ; V_{j}^{k}$ and $V_{j}^{k+1}$ are the previous and updated velocity of particle $j ; P_{\text {best }, j}$ and $G_{b e s t}$ are the best position of particle $j$ and the best position of the entire particle solutions; $c_{1}$ and $c_{2}$ are cognitive and social learning rates; $r_{1}$ and $r_{2}$ are the random number between 0 to $1 ; \omega, \omega_{\min }$, and $\omega_{\max }$ are represented the total weight, minimum weight and maximum weight; $i t_{i}$ and $i t_{\max }$ are number of current iteration and maximum iteration, respectively. For a robust and fast convergence PSO algorithm process, parameters of $c_{1}, c_{2}, \omega_{\min }$, and $\omega_{\max }$ are set to 2, 2, 0.4 and 0.9 as described in [12].

$$
\begin{aligned}
& X_{j}^{k+1}=X_{j}^{k}+V_{j}^{k+1} \\
& X_{j}^{k+1}=\omega V_{j}^{k}+c_{1} r_{j 1}+\left(P_{\text {best }, j}-X_{j}^{k}\right)+c_{2} r_{j 2}+\left(G_{\text {best }}-X_{j}^{k}\right) \\
& \omega=\omega_{\max }-\left(\omega_{\max }-\omega_{\min }\right)\left(\frac{i t_{i}}{i t_{\max }}\right)
\end{aligned}
$$

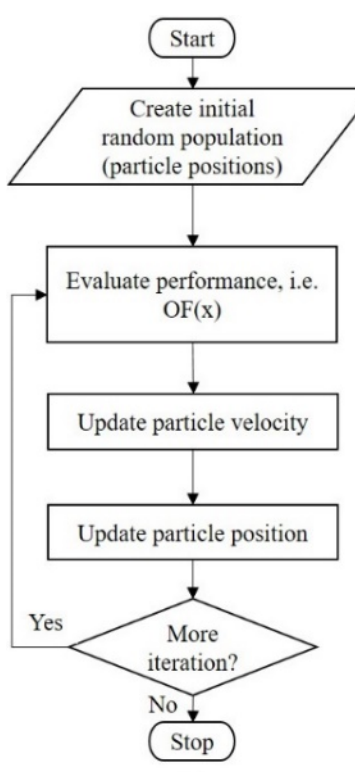

(a)

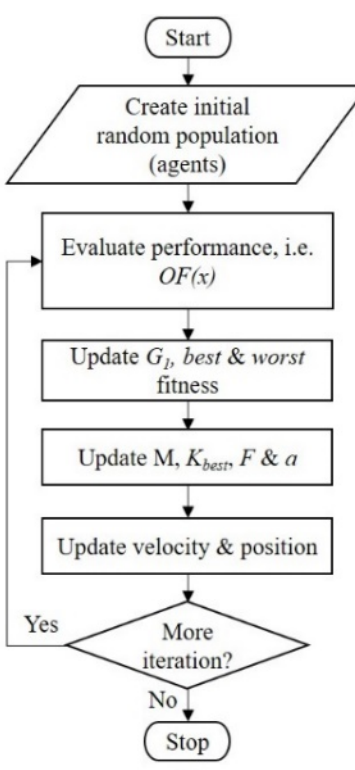

(b)

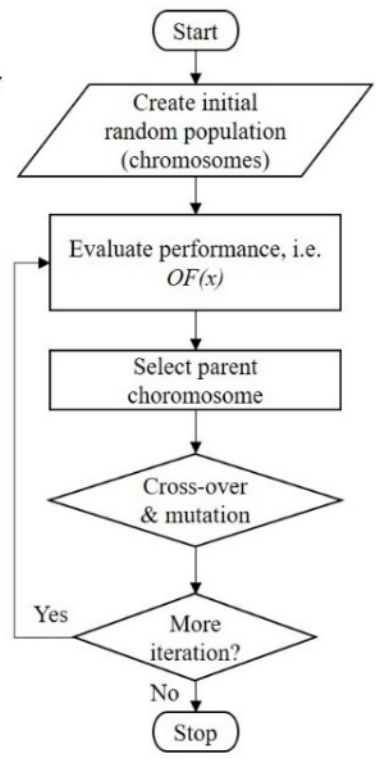

(c)

Figure 2. Optimization procedures using PSO, GSA and GA

\subsection{Gravitational search algorithm (GSA)}

GSA is an optimization algorithm based on Newton's famous law of gravity and mass interactions [25]. The simplified process of GSA algorithm is illustrated in Figure 2(b), where the process is started with the initializing the random agent population. In GSA, the updated position and velocity of the agent is calculated using (9) and (10), where $r_{i}$ is the random number between 0 to 1 and $a_{j}^{k}$ is an acceleration of the agent at the current iteration, respectively. The acceleration of the agent is obtained using (11), where $F_{j}^{k}$ and $M_{j, i n t}^{k}$ are the total force that acts on agent and the inertial mass of the agent,

$$
\begin{aligned}
& X_{j}^{k+1}=X_{j}+V_{j}^{k+1} \\
& X_{j}^{k+1}=r V_{j}^{k}+a_{j}^{k}
\end{aligned}
$$




$$
a_{j}^{k}=F_{j}^{k} / M_{j, i n t}^{k}
$$

\subsection{Genetic algorithm (GA)}

GA is an algorithm inspired by the process of natural evolution. GA algorithm has been successfully applied to a wide range of real-world problem of significant complexity. Starting with a randomly generated population (chromosomes), GA algorithm uses three main types of rules (selection, crossover, and mutation) at each step to produce a successor population for the next generation as illustrated in Figure 2(c). During selection rules, the parent chromosome that contributes to the population is selected for the next generation process. The selected parent chromosomes are re-combined to produce child chromosomes. These processes are iterated until the satisfactory fitness level is reached.

\subsection{Validation of an optimal battery model}

The optimal Li-ion battery model in the simulation is validated based on the typical discharge characteristics curve of Panasonic Li-ion CGR18650AF from the manufacturer following the procedures in [16]. During validation, the constant battery current are set at $0.2 \mathrm{C}(0.43 \mathrm{~A}), 1 \mathrm{C}(2.15 \mathrm{~A})$ and $2 \mathrm{C}(4.3 \mathrm{~A})$. The results are as shown in the results and discussion section.

\subsection{Simulation set-up for battery model parameter optimization}

Figure 3 illustrates the overall simulation set-up diagram for optimization of battery parameters. During the optimization of the battery parameters process, the developed battery model in Matlab/Simulink is linked to the PSO/GSA/GA algorithm in the Matlab/M-file as presented in Figure 3. Meanwhile, the typical discharge data from the manufacturer data is saved in Matlab/MAT-file. Before the optimization process is started, the population number, dimension number, and iterations are initially set to 25,6 and 100 for all algorithms, respectively. The optimization process by PSO, GSA and GA algorithm is illustrated in Figure 2(a)-(c). The processes are started with the randomly set of the initial population for each battery control parameters. The generated random parameters are evaluated by using a fitness function in (5). The process is repeatedly executed until the optimal parameters of battery are determined.

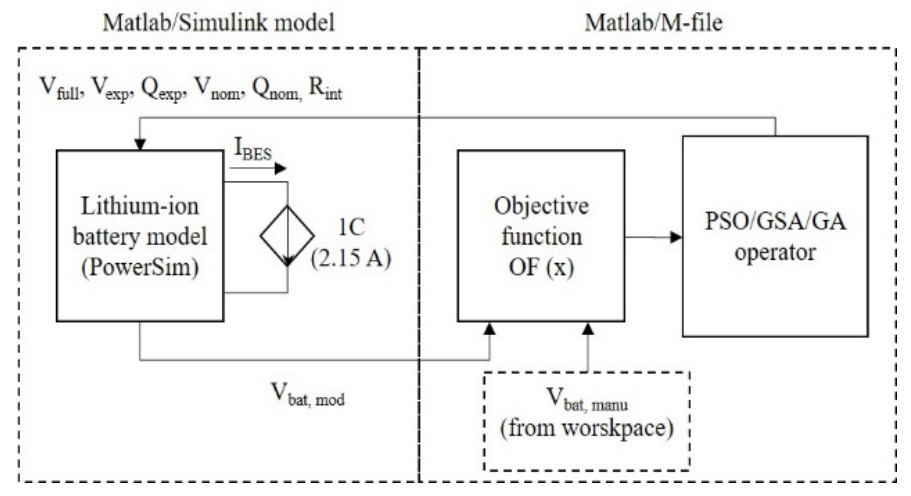

Figure 3. Simulation set-up of the battery parameters optimization

\section{RESULTS AND DISCUSSION}

The development process of the Li-ion battery model is started in the Matlab/Simulink. Then, the process is continued with the battery parameters optimization. Finally, the validation of the optimal battery model using typical discharge curves of a real battery from the manufacturer is carried out. The complete results of the battery's parameters optimization are presented in the following sub-section.

\subsection{Optimization of battery model parameters}

Table 2 illustrates the comparison of the obtained battery parameters for the cases of manual and optimization (PSO, GSA, and GA) approaches. Besides that, the performance and elapsed time of optimization approaches also presented. From Table 2, the GA approach converged faster compared to the other approaches with the elapsed time of $1680 \mathrm{~s}$. While, for PSO and GSA the elapsed time is $2013 \mathrm{~s}$ and $1760 \mathrm{~s}$, respectively. It is also observed that the GA approach is converged at the $28^{\text {th }}$ number of iterations, while PSO and GSA are converged at the iteration of 38 and 75 as illustrated in Figure 4, respectively. 
Table 2. Comparison of battery parameters based on manual, PSO, GSA and GA approaches

\begin{tabular}{ccccc}
\hline Parameters & \multicolumn{4}{c}{ Parameters extracted approaches } \\
(unit) & Manual & PSO & GSA & GA \\
\hline$V_{\text {nom }}(\mathrm{V})$ & 3.3000 & 3.2201 & 2.8791 & 2.9114 \\
$Q_{\text {nom }}(\mathrm{Ah})$ & 1.8100 & 2.1164 & 2.1657 & 2.1738 \\
$E_{0}(\mathrm{~V})$ & 3.6971 & 3.5246 & 3.6125 & 3.7137 \\
$R_{\text {int }}(\Omega)$ & 0.0165 & 0.0701 & 0.1064 & 0.1422 \\
$K$ & 0.0265 & 0.0038 & 0.0050 & 0.0044 \\
$A(\mathrm{Ah})$ & 0.4194 & 0.6806 & 0.6214 & 0.5917 \\
$B\left(\mathrm{Ah}^{-1}\right)$ & 4.6152 & 1.6488 & 1.4669 & 1.7049 \\
$Q_{\text {rated }}(\mathrm{Ah})$ & \multicolumn{4}{c}{2.2500} \\
$Q_{\max }(\mathrm{Ah})$ & \multicolumn{5}{c}{2.2500} \\
$V_{\text {full }}(\mathrm{V})$ & 4.2000 & 4.1351 & 4.1275 & 4.1632 \\
$I_{\text {dis, nom }}(\mathrm{A})$ & \multicolumn{4}{c}{1.0000} \\
$V_{\text {exp }}(\mathrm{V})$ & 3.6400 & 3.4287 & 3.3421 & 3.5421 \\
$Q_{\text {exp }}(\mathrm{Ah})$ & 0.6500 & 1.8195 & 2.0451 & 1.7597 \\
Elapsed time $(\mathrm{s})$ & - & 2013.6 & 1760.1 & 1680.1 \\
OF $(x)$ & - & 0.1754 & 0.2532 & 0.1689 \\
\hline
\end{tabular}

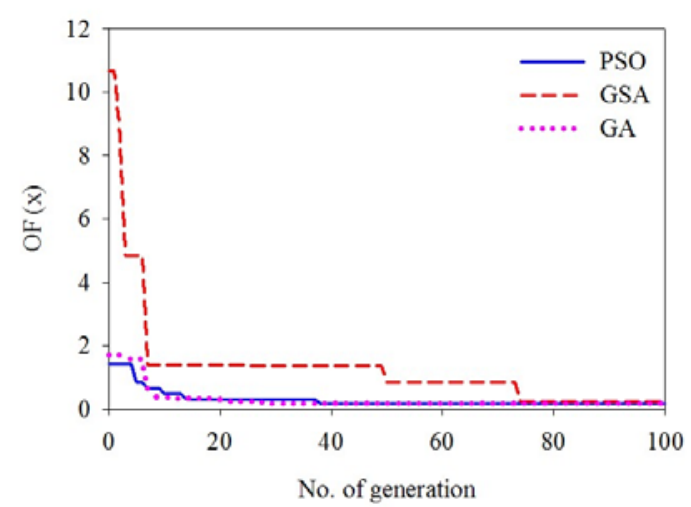

Figure 4. The performance of the heuristic optimization methods in terms of fitness function

In terms of accuracy, the GA approach is performing the highest accuracy with the final value of the fitness function, $\mathrm{OF}(x)$ is 0.1689 , while for PSO and GSA are 0.1754 and 0.2532 , respectively. Therefore, for further simulation study, the battery parameters obtained by the GA approach will be used. Besides that, Figure 5 illustrates the comparison between the discharge curve from the battery manufacturer and the simulated discharge curves generated by PSO, GSA and GA approach, respectively. From the figure, it is proven that by using the optimization method, the battery model accuracy significantly increased.

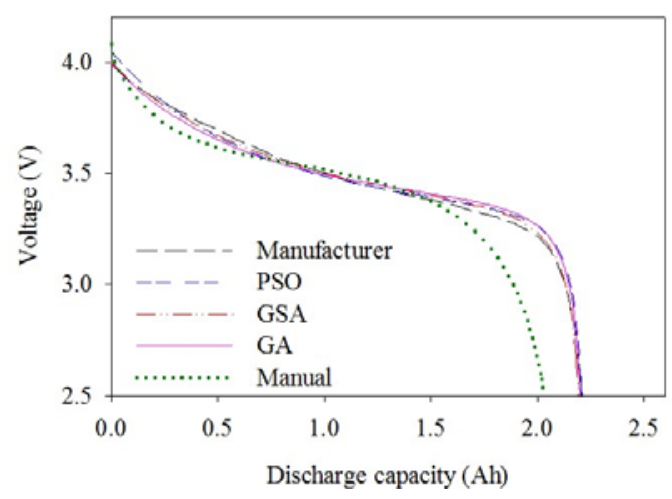

Figure 5. A comparison between the discharge curve from the battery manufacturer and simulated discharge curves generated by PSO, GSA, and GA optimization approaches 


\subsection{Validation of BES model}

The developed Li-ion battery model utilizing optimal battery parameters obtained from the GA algorithm have been reconstructed to validate its discharge curves performances at different discharge currents. The discharge current range considered is based on nominal rating at $1 \mathrm{C}$, higher $(2 \mathrm{C})$ and lower $(0.2 \mathrm{C})$. The results with respect to the manufacturer's data are as shown in Figure 6. Based on the results, it is observed that the discharge characteristics curves of developed Li-ion model match very well with the typical discharge characteristic curves of Panasonic Li-ion CGR18650AF with the overall accuracy of up to $98 \%$. It clearly shows that the accuracy of the developed model depends on the precision of the extracted parameters data from the typical discharge curves.

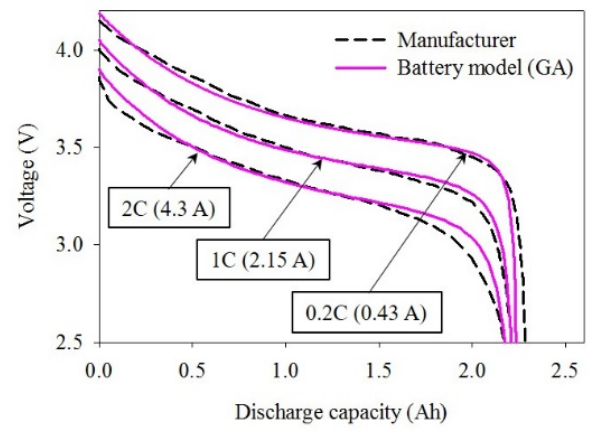

Figure 6. Validation of the discharge characteristics between the developed Li-ion battery model in matlab/simulink and real battery model (3.3 V, $2.25 \mathrm{Ah})$

\section{CONCLUSION}

An easy to use and accurate battery model parameter identification strategy is introduced using a heuristic optimization approach. The Tremblay's Li-ion battery model is developed in Matlab/Simulink based on the formulated equations, in which the parameters are obtained from different optimization approaches of PSO, GSA and GA algorithms. From the optimization results of the model developed based on Panasonic Li-ion CGR 18650AF battery test data, the GA algorithm showed the best performance with the fitness function and elapsed time of 0.1689 and $1680 \mathrm{~s}$, respectively. The accurate battery model obtained by the GA algorithm was further validated by comparing the discharge curves of the developed battery model with the discharge curves from the manufacturer. The results showed that the GA-based optimal battery model gives an accuracy of up to $98 \%$. Therefore, the obtained battery parameters by using the GA algorithm can be used in further simulation study related to the controller design of the lithium batteries.

\section{ACKNOWLEDGEMENTS}

The authors would like to acknowledge financial support by Universiti Malaysia Terengganu and Ministry of Education, Malaysia under the Fundamental Research Grant Scheme (FRGS) Vot No. 59418.

\section{REFERENCES}

[1] H. C. Hesse, M. Schimpe, D. Kucevic and A. Jossen, "Lithium-ion battery storage for the grid - A review of stationary battery storage system design tailored for applications in modern power grids," Energies, vol. 10, No 12, pp. 1-42, 2017.

[2] M. A. Hannan, M. M. Hoque, A. Mohamed and A. Ayob, "Review of energy storage systems for electric vehicle applications: Issues and challenges," Renewable and Sustainable Energy Reviews, vol. 69, pp. 771-789, 2017.

[3] S. Shivashankar, S. Mekhilef, H. Mokhlis and M. Karimi, "Mitigating methods of power fluctuation of photovoltaic (PV) sources - A review," Renewable and Sustainable Energy Reviews, vol. 59, pp. 1170-1184, 2016.

[4] M. Delfanti, D. Falabretti and M. Merlo, "Energy storage for PV power plant dispatching," Renewable Energy, vol. 80, pp. 61-72, 2015.

[5] M. Yekini Suberu, M. Wazir Mustafa and N. Bashir, "Energy storage systems for renewable energy power sector integration and mitigation of intermittency," Renewable and Sustainable Energy Reviews, vol. 35, pp. 499-514, 2014. 
[6] W. Sutopo and E. A. Kadir, "Designing framework for standardization case study: Lithium-ion battery module in electric vehicle application," International Journal of Electrical and Computer Engineering, vol. 8, no. 1, p. 220. 2018.

[7] M. A. Jusoh and M. Z. Daud, "Particle swarm optimisation-based optimal photovoltaic system of hourly output power dispatch using Lithium-ion batteries," Journal of Mechanical Engineering and Sciences, vol. 11, no. 3, pp. 2780-2793, 2017.

[8] J. S. Huh, W. S. Moon, H. S. Shin, K. H. Ryu and J. C. Kim, "New control scheme for a battery energy storage system for output stabilization of a wind generator," Proceedings of the IEEE Power Engineering Society Transmission and Distribution Conference, pp. 1-5, 2014.

[9] H. Zhao, Q. Wu, C. Wang, L. Cheng and C. N. Rasmussen, "Fuzzy logic based coordinated control of battery energy storage system and dispatchable distributed generation for microgrid," Journal of Modern Power Systems and Clean Energy, vol. 3, No. 3, pp. 422-428, 2015.

[10] F. Luo, K. Meng, Z. Y. Dong, Y. Zheng, Y. Chen and K. P. Wong, "Coordinated operational planning for wind farm with battery energy storage system," IEEE Transactions on Sustainable Energy, vol. 6, no. 1, pp. 253-262, 2015.

[11] M. A. Jusoh and M. Z. Daud, "Control strategy of a grid-connected photovoltaic with battery energy storage system for hourly power dispatch," International Journal of Power Electronics and Drive Systems (IJPEDS), vol. 8, No. 4, pp. 1830-1840, 2017.

[12] M. Z. Daud, A. Mohamed and M. A. Hannan, "An improved control method of battery energy storage system for hourly dispatch of photovoltaic power sources," Energy Conversion and Management, vol. 73, pp. 256-270, 2013.

[13] M. Z. Daud, A. Mohamed, A. A. Ibrahim and M. A. Hannan, "Heuristic optimization of state-of-charge feedback controller parameters for output power dispatch of hybrid photovoltaic/battery energy storage system," Measurement: Journal of the International Measurement Confederation, vol. 49, no. 1, pp. 15-25, 2014.

[14] A. Zainuri, U. Wibawa, M. Rusli, R. N. Hasanah and R. A. Harahap, "VRLA battery state of health estimation based on charging time," Telekomnika, vol. 17, no. 3, p. 1577, 2019.

[15] S. M. M. Mousavi G. and M. Nikdel, "Various battery models for various simulation studies and applications," Renewable and Sustainable Energy Reviews, vol. 32, pp. 477-485, 2014.

[16] O. Tremblay and L. A. Dessaint, "Experimental validation of a battery dynamic model for EV applications," World Electric Vehicle Journal, vol. 3, no. 2, pp. 289-298, 2009.

[17] Y. Zhang, S. Lyden, B. A. L. De La Barra and M. E. Haque, "Optimization of tremblay's battery model parameters for plug-in hybrid electric vehicle applications," 2017 Australasian Universities Power Engineering Conference (AUPEC), pp. 1-6, 2017.

[18] Y. Wang and L. Li, "Li-ion battery dynamics model parameter estimation using datasheets and particle swarm optimization," International Journal of Energy Research, vol. 40, no. 8, pp. 1050-1061, 2016.

[19] L. Wang, Z. Zhang, C. Huang and K. L. Tsui, "A GPU-accelerated Parallel Jaya Algorithm for efficiently estimating Li-ion battery model parameters," Applied Soft Computing Journal, vol. 65, pp. 12-20, 2018.

[20] "Lithium-ion Batteries: Individual data sheet," 2019 [Online]. Available: $\mathrm{http}: / / w w w . h o u s e o f b a t t e r i e s . c o m / d o c u m e n t s / C G R 18650 A F . p d f$. [Accessed: 24-Feb-2019].

[21] M. Nadour, A. Essadki, T. Nasser and M. Fdaili, "Robust coordinated control using backstepping of flywheel energy storage system and DFIG for power smoothing in wind power plants," International Journal of Power Electronics and Drive Systems (IJPEDS), vol. 10, no. 2, p. 1110, 2019.

[22] Hlal A, Ramachandaramurthya V., Sanjeevikumar P., Pouryekta Aref, Kaboli Hamid Reza, Tuan Ab Rashid bin Tuan Abdullah, "NSGA-II and MOPSO based optimization for sizing of hybrid PV/wind/battery energy storage system," International Journal of Power Electronics and Drive Systems (IJPEDS), vol. 10, no. 1, pp. 463-478, 2019.

[23] J. S. Norbakyah and A. R. Salisa, "Optimization of the fuel economy and emissions for plug in hybrid electric recreational boat energy management strategy using genetic algorithm," International Journal of Power Electronics and Drive Systems (IJPEDS), vol. 10, no. 2, pp. 792, 2019.

[24] R. C. Eberhart and J. Kennedy, "Particle swarm optimization in neural networks," IEEE International Conference, pp. 1942-1948, 1995.

[25] E. Rashedi, H. Nezamabadi-pour and S. Saryazdi, "GSA: A Gravitational Search Algorithm," Information Sciences, vol. 179 , no. 13 , pp. 2232-2248, 2009.

Int J Pow Elec \& Dri Syst Vol. 11, No. 1, Mar 2020 : 333 - 341 


\section{BIOGRAPHIES OF AUTHORS}

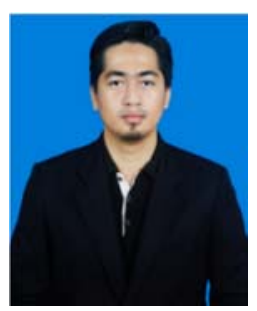

Mohd Afifi Jusoh was born in Pasir Mas, Kelantan, in 1989. He received the bachelor's degree in Electrical Engineering from University Teknologi MARA (UiTM), Shah Alam, Malaysia in 2013. He worked as electrical engineer at electrical switchgear company during the years of 2013 and 2015. In 2018, he completed his M.Sc. degree in Physics from the Universiti Malaysia Terengganu (UMT), Malaysia. He is currently pursuing PhD degree in Physics at Universiti Malaysia Terengganu (UMT) focusing in wave energy generation system. His current research interests include renewable energy, ocean wave energy conversion and electrical and mechanical control system

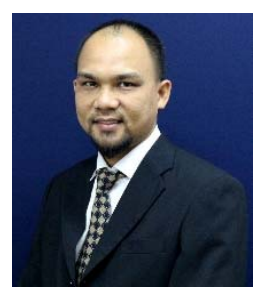

Muhamad Zalani Daud was born in Tumpat, Kelantan Malaysia in 1978. He completed his bachelor's Degree in electrical and electronic engineering, Ritsumeikan University, Kyoto, Japan in March 2003. In July 2007 he pusue his study at School of Electrical, Computer and Telecommunications Engineering (SECTE), University of Wollongong, Australia and completed his MSc. in February 2010. In December the same year, he started his $\mathrm{PhD}$ study at the Universiti Kebangsaan Malaysia (UKM), Faculty of Engineering and Built Environment (FKAB). He then finished his PhD research study in April 2014. He is currently a senior lecturer at the Universiti Malaysia Terengganu (UMT), Faculty of Ocean Engineering Technology and Informatics in which his research interests are in energy storage application for renewable energy integration and smart meter development for energy efficiency studies. 